\title{
Sequência Didática como estratégia para ensino sobre desafios socioambientais relacionados às Mudanças Climáticas
}

Didactic sequence as a strategy for teaching about the socio-environmental challenges related to Climate Change Daniela Resende de Faria ${ }^{1}$, Maria Carolina Ramos ${ }^{2}$, Prisclia Pereera Coltri ${ }^{3}$

1 - Doutoranda, Programa de Pós-Graduação em Ensino e História de Clências da Terra, (PPG-EHCT), Universidade Estadual de Campinas. Campinas, SP, Brasil.

2 - Doutoranda em Direito, Universidade Autônoma de lisboa, Portugal. Doutoranda, Programa de Pós-Graduação em Ensino e História de Ciências da Terra, (PPG-EHCT), Universidade Estadual de Campinas. Campinas, SP, Brasil.

3 - Diretora do Centro de Pesquisas Meteorológicas e Climáticas Aplicadas à Agricultura (Cepagri), Docente do Programa de Pós-Graduação em Ensino e História de Clências da Terra, (PPG-EHCT), Universidade Estadual de Campinas, Campinas, SP, Brasil. Pesquisadora CNPQ.

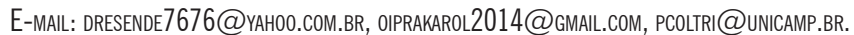

\begin{abstract}
Socio-environmental issues related to climate change are still poorly addressed and studied in basic education, especially at the high school level. Deeply related to urban problems that affect communities, the most vulnerable populations are those who are most likely to be more impacted from its consequences. Based on the understanding that everyone has the right to a balanced environment for their survival, this study aims to present a didactic sequence for teaching socio-environmental issues within the theme "Climate Change" on line with the Common National Curricular Base. The didactic sequence was developed based on Project Based Learning (PBL) and its development will promote a protagonist role of students, based on current issues, which fosters the development of critical thinking for the understanding of a complex reality, helping the insertion of the topic of climate change in the high school stage.
\end{abstract}

Resumo: Questões socioambientais ligadas às mudanças climáticas ainda são pouco trabalhadas e estudadas na Educação Básica, sobretudo na etapa do Ensino Médio. Profundamente relacionadas aos problemas urbanos que atingem as comunidades, são as populações mais vulneráveis aquelas que estão mais propensas a serem impactadas com suas consequências. Partindo do entendimento de que todos têm direito a um meio ambiente equilibrado para a sua sobrevivência, este estudo tem como objetivo apresentar uma sequência didática para 0 ensino da temática socioambiental dentro do tema "Mudanças Climáticas" em consonância com a Base Nacional Comum Curricular (BNCC). A sequência didática foi elaborada com base na Aprendizagem Baseada em Projetos (ABP) e seu desenvolvimento pretende promover uma atuação protagonista dos estudantes, fundamentada em temas da atualidade, 0 que fomentará o desenvolvimento do pensamento crítico para a compreensão de uma realidade complexa, auxiliando a inserção do tema mudanças climáticas na etapa do Ensino Médio.
Citation/Citação: Faria, D. R. de, Ramos, M. C., \& Coltri, P. P. (2021). Sequência Didática como estratégia para ensino sobre desafios socioambientais relacionados às Mudanças Climáticas. Terræ Didatica, 17(Publ. Contínua), 1-12, e021052. doi: 10.20396/td.v17i00.8667126.

\section{Keywords: Education, Teaching, Climate Change, Geosciences, Project Based Learning.}

Palavras-chave: Educação, Ensino, Mudanças Climáticas, Geociências, Aprendizagem Baseada em Projetos.

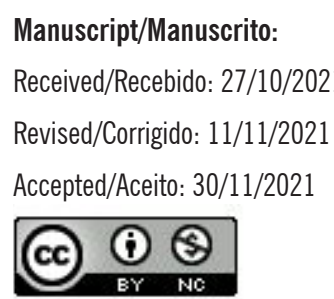

\section{Introdução}

Desde o primeiro relatório do Painel Intergovernamental de Mudanças Climáticas (IPCC, sigla em inglês), em 1990, a sociedade já vem sendo alertada sobre os problemas socioambientais consequentes das mudanças no clima. A cada novo relatório publicado pela organização, os alertas se tornam mais frequentes, mas se observa que eles têm sido pouco abordados nas políticas públicas educacionais brasileiras. Como resultado, além de consequências diretas na sociedade, existe falta de conhecimento público sobre um de seus direitos fundamentais: o direito a um clima equilibrado.
Portanto, um meio ambiente ecologica e climaticamente equilibrado é essencial para que todos os indivíduos integrantes da sociedade possam gozar de uma vida digna, sendo este um direito fundamental do cidadão.

O conceito do clima equilibrado como um direito fundamental se insere na abordagem do direito climático (Sarlet \& Fensterseifer, 2021). Assim, o direito climático nasce a partir da necessidade cada vez mais premente de que todos os seres tenham acesso a um clima estável e que este venha a ser reconhecido como um direito fundamental.

\begin{tabular}{c|c|c|c|c|c}
\hline (C) Terrae Didat. & Campinas, SP & v.17 & $1-12$ & $\mathrm{e} 021052$ & 2021 \\
\hline
\end{tabular}


Um clima limpo, seguro e estável, deriva do regime constitucional de proteção ecológica e, em particular, do direito fundamental ao meio ambiente, previsto na Constituição Federal do Brasil de 1988. Deriva ainda dos deveres do Estado quanto à proteção do sistema climático, conforme previsto diretamente no inciso I no $\$ 1^{\circ}$ do artigo 225 da Constituição, que dispõe sobre a proteção dos processos ecológicos essenciais (Brasil, 1988, Sarlet \& Fensterseifer, 2021). Tal compreensão fornece instrumentos jurídicos para a população exercer seus direitos, criando mecanismos de compreensão crítica das práticas em sociedade, além de fundamentar medidas de adaptação e mitigação às Mudanças Climáticas. No processo, segundo Palma (2018), constituem elementos fundamentais a educação ambiental e em mudanças climáticas, abordando assuntos como direitos básicos dos cidadãos em relação ao clima.

Em 2017, a Educação Brasileira foi normatizada pela Base Nacional Comum Curricular (BNCC), que trouxe novos desafios à área, inclusive no que tange ao tema interdisciplinar e transversal das Mudanças Climáticas, que precisam ser trabalhadas de forma plural e fluida, a fim de abranger suas complexidades e incertezas, engajando e promovendo o protagonismo dos alunos.

A Aprendizagem Baseada em Projetos (ABP) pode ser poderosa estratégia metodológica para a exploração conceitual reflexiva, já que fomenta o trabalho com problemas reais, do cotidiano dos estudantes. $\mathrm{O}$ ensino por meio de ABP é apropriado para preparar os alunos com habilidades de resolução de problemas e tecnologias do século XXI (Bender, 2014, pp. 25). Sagala et al. (2019) corroboram a ideia, ao enfatizar que a tomada de consciência acerca da realidade é fomentada principalmente por meio de processos de ensino e de aprendizagem significativos, capazes de transformar o pensamento dos estudantes.

Nesse contexto, a questão norteadora deste trabalho foi: se reconhecemos as mudanças climáticas como geradoras potenciais de problemas socioambientais, sobretudo no meio urbano, é possível inserir noções básicas sobre otema, associadas ao direito fundamental do cidadão, à luz da BNCC, na etapa do Ensino Médio?

O pressuposto do trabalho é que temas complexos dentro do assunto "Mudanças Climáticas", como a habitação urbana e suas inter-relações com as questões ambientais e humanas, podem ser abordados em sequências didáticas fundamentadas na Metodologia da Aprendizagem Baseada em Projetos (ABP) na etapa do Ensino Médio. Dessa forma, foi elaborada uma proposta para o ensino e aprendizagem de mudanças climáticas de acordo com as prerrogativas da BNCC, representada por uma sequência didática baseada nos princípios da ABP. O desafio socioambiental ligado às Mudanças Climáticas, eleito para a sequência didática, foi a questão da habitação e moradia nos centros urbanos, sua relação com o clima e com o direito fundamental do cidadão.

\section{Direitos humanos e mudanças climáticas: os desafios socioambientais urbanos}

A emergência climática é um dos grandes desafios do século XXI (Artaxo, 2020). As consequências das mudanças no padrão das variáveis meteorológicas, bem como das concentrações de gases de efeito estufa liberados no ambiente, afetam desproporcionalmente as populações (Levy \& Patz, 2015). Pessoas mais pobres dos países desenvolvidos e as comunidades dos países subdesenvolvidos são as mais afetadas (Sinden, 2007), em um quadro que acarreta problemas relacionados a direitos humanos e justiça social (Sachs, 2008).

Há uma necessidade urgente de orientação pública para gerenciar as consequências ambientais causadas pelas Mudanças Climáticas, requerendo uma consciência jurídica (Blank, 2015). Quanto aos entes estatais legitimados constitucionalmente para corrigir tais situações perante o Poder Judiciário, Souza (2008) destaca, além do Ministério Público, o papel constitucional da Defensoria Pública, já que, na grande maioria das vezes, quando da violação à garantia do mínimo existencial ecológico, as pessoas atingidas certamente comporão os entes mais vulneráveis e marginalizados da população brasileira.

O Direito Ambiental brasileiro é composto por um vasto arcabouço de normativos jurídicos, que visa dar cumprimento ao Texto Constitucional no tocante à defesa, proteção, preservação e conservação dos recursos naturais existentes no território nacional (Fernandes, 2020). A mesma autora ainda destaca que, como a intervenção humana no meio ambiente introduz a possibilidade de colocar em risco ou até mesmo destruir o próprio habitat, faz-se necessária a intervenção estatal para implementação de políticas públicas que sejam eficazes à manutenção do meio ambiente.

Um dos maiores desafios em relação aos problemas socioambientais é a questão da habitação e moradia nos centros urbanos (Grostein, 2001, 
Santos \& Bacci, 2017). O parcelamento do solo é o instituto jurídico pelo qual se constrói o delicado mosaico que compõe os atuais centros urbanos. Atualmente, grande parte do território urbano no Brasil tem se constituído mediante parcelamento irregular do solo, realizado, segundo Pacheco (2014), completamente à margem da legislação urbanística, ambiental, civil e penal, promovendo aberturas de ruas e demarcação de lotes sem qualquer controle do Poder Público.

As consequências negativas das ocupações irregulares são inúmeras, dentre elas, ressalta-se a precariedade das condições de habitação e moradia, sem saneamento ou acesso à infraestrutura mínima e demais benefícios extremamente prejudicados e/ ou inexistentes, sem contar a poluição, contaminação de corpos hídricos pelo esgoto e pelo lixo sempre muito próximo e presente (Santos \& Bacci, 2017). As consequências afetam tanto os habitantes da cidade, como o próprio clima local.

Pacheco (2014) pondera que a necessidade de manutenção de áreas de proteção ambiental no meio urbano é um instrumento jurídico imprescindível para a garantia da qualidade de vida da população e para a manutenção saudável das cidades. Portanto um meio ambiente ecologicamente equilibrado constitui requisito essencial para que todos os indivíduos integrantes da sociedade possam gozar de uma vida minimamente digna, evidenciando-se como um verdadeiro direito fundamental do cidadão (Brasil, 1988, Sarlet \& Fensterseifer, 2021).

Considerando que as alterações climáticas também podem resultar em danos a bens individuais, o direito fundamental à propriedade impõe igualmente ao Estado um dever de proteção, no que diz respeito aos riscos causados pelas alterações climáticas (Barcellos et al., 2009). Segundo Sarlet \& Fensterseifer (2021), a estabilidade e integridade climática agregam tanto o núcleo essencial presente no direito fundamental ao meio ambiente, quanto o conteúdo do chamado mínimo existencial ecológico, podendo-se falar de um mínimo existencial climático. Os autores ainda ressaltam que a criação e estruturação de um sistema climático deve, dessa forma, ser reconhecido como um novo bem jurídico de estatura constitucional.

Recentemente o Superior Tribunal de Justiça reconheceu nos autos do Recurso Especial $\mathrm{n}^{\circ} 1.000 .731$, a consagração expressa da proteção da integridade do sistema climático no Novo Código Florestal, Lei n.12.651/2012, previsto no artigo $1^{\circ}$-A, parágrafo único, e também na Lei da Política Nacional sobre Mudança do Clima, Lei n.12.187/2009, no artigo $4^{\circ}$, inciso I (Brasil, 2009). Ramacciotti et al. (2020) assinalam que o reconhecimento de uma nova e fortalecida dimensão climática, inerente ao regime constitucional ecológico, estabelecido pela Constituição Federal de 1988, traz a necessidade de caracterização de deveres específicos de proteção e promoção de instrumentos organizacionais e procedimentais para o combate, contenção e diminuição das causas e consequências das mudanças climáticas, possibilitando que, no caso de descumprimento por ação e/ou omissão, o controle jurisdicional dos direitos sirva como parâmetro material para a aplicação do princípio da proibição ao chamado retrocesso no que tange ao direito climático.

$\mathrm{Na}$ mesma direção, a Assembleia Geral da ONU apresentou informe no qual examina a necessidade urgente de ações para garantir um clima seguro para a humanidade. No documento, o relator especial para Direitos Humanos e Meio Ambiente assinala que:

Em termos de obrigações substantivas, os Estados não devem violar o direito a um ambiente seguro pelas suas próprias ações; devem impedir que esse direito seja violado por terceiros, especialmente empresas, e devem estabelecer, implementar e fazer cumprir leis, políticas e programas para implementar esse direito. Estados também devem evitar a discriminação e medidas retrocessivas. Todas as medidas relacionadas ao clima, incluindo as obrigações relacionadas à mitigação, adaptação, financiamento e perdas e danos, são regidas por esses princípios (ONU, 2019).

Assim, é necessário tecer algumas considerações sobre direitos humanos e direitos fundamentais. Direitos Humanos são todos aqueles relacionados à liberdade e à isonomia no plano internacional. Já os direitos fundamentais são os direitos humanos já inseridos na Constituição Federal. Piovesan (2009) ressalta que o conteúdo dos dois é essencialmente o mesmo; o que difere é o plano em que estão consagrados. A mesma autora coloca que os direitos humanos se inspiram na dupla vocação para afirmar a dignidade humana e prevenir o sofrimento humano.

A própria Constituição Federal evidencia a preocupação com a formação e construção de um Estado Democrático de Direito, fundado na dignidade da pessoa humana e na cidadania plena como componentes dos princípios lógicos e orientadores nas

\begin{tabular}{c|c|c|c|c|c}
\hline (C) Terrae Didat. & Campinas, SP & v.17 & $1-12$ & $\mathrm{e} 021052$ & 2021 \\
\hline
\end{tabular}


relações institucionais em território brasileiro. $\mathrm{O}$ artigo 225 da Constituição Federal prevê que todos têm direito ao meio ambiente ecologicamente equilibrado, bem de uso comum do povo e essencial à sadia qualidade de vida; impõe-se ao Poder Público e à coletividade o dever de defendê-lo e preservá-lo para as presentes e futuras gerações (Brasil, 1988). Ademais, foi criado o Plano Nacional de Educação em Direitos Humanos (PNEDH, 2007) como política pública baseada nos princípios da democracia, cidadania e justiça social, sendo um instrumento de construção de uma cultura de direitos humanos, de responsabilidade dos Governos Federal e Estaduais, com a finalidade de consolidar uma cultura de direitos humanos em conjunto com a sociedade, para contribuir com o aperfeiçoamento do Estado Democrático de Direito (Brasil, PNEDH, 2007).

O PNEDH é uma política pública baseada nos princípios da democracia, cidadania e justiça social, no plano da educação formal e não formal; assim, traz a necessidade de mobilização e organização de processos participativos na educação em defesa dos direitos humanos e também proteção de grupos em situação de risco e maior vulnerabilidade social. Em suas ações programáticas o Plano Nacional de Educação em Direitos Humanos objetiva tornar a educação em direitos humanos um elemento relevante para a vida dos estudantes e dos trabalhadores da educação, envolvendo-os em um diálogo sobre maneiras de aplicar os direitos humanos em sua prática cotidiana (Brasil, PNEDH, 2007).

Com o advento das Diretrizes Nacionais para Educação em Direitos Humanos (DNEDH) (Brasil, 2012), e educação ocupa posição fundamental para o acesso ao legado histórico dos Direitos Humanos, assim como para a compreensão de que a cultura dos Direitos Humanos e sua inserção na educação é um dos alicerces necessários para a mudança social. Por isso, fortalecer a educação em direitos humanos promove a mudança e a transformação social necessárias, para efetivar o princípio da sustentabilidade socioambiental (Brasil, DNEDH, 2012).

\section{Temas socioambientais, ensino de mudanças climáticas e BNCC}

A BNCC, documento normativo da Educação Básica brasileira, traz mudanças significativas, preconizando os direitos de aprendizagem e uma educação integral, tornando-se a referência para a elaboração dos currículos e das aulas das compo- nentes curriculares a serem ministradas na Educação Básica no país. Seu foco não está mais no ensino e sim na aprendizagem e, justamente por conta disso, sua essência é o desenvolvimento de competências. Para tanto, prevê dez competências gerais, a serem desenvolvidas por todos os componentes curriculares ao longo de toda a Educação Básica.

A etapa do Ensino Médio está organizada em Áreas do Conhecimento e nelas se encontram as competências específicas,

(...) para assegurar o desenvolvimento das competências específicas de cada área, cada uma delas está relacionada a um conjunto de habilidades, que representa as aprendizagens essenciais a serem garantidas no âmbito da BNCC a todos os estudantes (Zezzo et al., 2020, p. 02).

Com isso, as aulas da Educação Básica devem promover a articulação teórico-prática, de modo que os estudantes sejam capazes de mobilizar o conteúdo conceitual para a resolução de problemas reais, já que:

$\mathrm{Na}$ BNCC, competência é definida como a mobilização de conhecimentos (conceitos e procedimentos), habilidades (práticas, cognitivas e sócio-emocionais), atitudes e valores para resolver demandas complexas da vida cotidiana, do pleno exercício da cidadania e do mundo do trabalho (Brasil, 2018, p. 08).

Morin (2015, p. 06) aponta para o desafio da atualidade no que se refere à educação: "Trata-se de exercer um pensamento capaz de lidar com o real, de com ele [o real] dialogar e negociar". Portanto, o professor se vê diante da necessidade de organizar suas aulas e práticas pedagógicas de forma a proporcionar meios e ferramentas para que seus alunos sejam capazes de interpretar, interagir, viver, conviver e transformar a realidade complexa. Em aulas que tenham como pressuposto uma organização linear e sedimentada em conteúdo, assentadas sob práticas na qual o professor não promova a apreensão da realidade estão fadadas ao fracasso, e como Morin (2015) aponta, não geram engajamento $\mathrm{e}$, por isso, não atendem à proposta $\mathrm{da}$ educação integral nem garantem a aprendizagem.

A Educação Integral, princípio essencial da BNCC, se alicerça sobre alguns pilares, dos quais se considera a complexidade o principal deles. Dessa forma, a aprendizagem ocorre mediante uma articulação entre competências e habilidades, tanto do conhecimento específico relacionado às 
mudanças climáticas, quanto de outros, ou seja, em caráter interdisciplinar. Faria \& Vaz (2018, p. 164) destacam que “(...) os conhecimentos de domínio geral e as estratégias de domínio científico são indissociáveis". Orion $(2019$, p.8) também destaca que a adoção de perspectivas interdisciplinares potencializa os sistemas de pensamento, já que “(...) elas viabilizam aos estudantes a integração de diversas componentes curriculares e a desenvolver a capacidade cognitiva para os sistemas de pensamento [tradução livre], o que corrobora o fato de que, na BNCC, “(...) o conteúdo não está necessariamente organizado por disciplinas (...)" o que "(...) implica o fortalecimento das relações de interdisciplinaridade e contextualização" (Zezzo et al., 2020, p. 03).

Entende-se daí que a interdisciplinaridade é fundamental na educação em mudanças climáticas e temas associados a ela. Deve ser fomentada e desenvolvida ao longo das componentes curriculares para que a aprendizagem assim se estruture, já que envolve o entendimento de muitos e múltiplos conceitos de diversas áreas do conhecimento. Por isso, não se trata unicamente de ensinar conteúdos e objetos de aprendizagem de uma ou outra componente curricular: trata-se de algo muito mais amplo e a interdisciplinaridade pode contribuir à “(...) necessidade de se formar o indivíduo para o exercício da cidadania e resolução de problemas oriundos do desenvolvimento, em que se torna imprescindível a formação do pensamento crítico" (Façanha et al., 2019, p. 43). A interdisciplinaridade, assim, "pode também permitir ao aluno adquirir visão mais abrangente e integrada do conteúdo, bem como compreensão crítica e abrangente do que é a ciência contemporânea" (Silva et al., 2008, p. 501).

A distância entre os conceitos e a contextualização, ou seja, práticas pedagógicas e caminhos didáticos descolados do contexto social e da realidade dos estudantes, não viabiliza a construção das competências senão de forma rasa. Por isso, ao final do Ensino Médio, os egressos da Educação Básica muitas vezes não conseguem distinguir fato de opinião: "o conhecimento precisa ser distinguido de opinião verdadeira em virtude de esta poder resultar de acaso, adivinhação ou palpite" (Oliva, 2011, p. 19).

De que forma um aluno pode olhar para um problema real que envolve a mudança climática e os temas relacionados a ela, como por exemplo, temas relacionados à habitação e moradia nas áreas urbanas e direitos do cidadão, por exemplo, e visualizar vários tipos de soluções, mobilizando competências?

Segundo Morin (2011), o desafio:

(...) É o problema universal de todo cidadão do novo milênio: como ter acesso às informações sobre o mundo e como ter a possibilidade de articulá-las e organizá-las? Como perceber e conceber o contexto, o global (a relação todo/ partes), o multidimensional, o complexo? Para articular e organizar os conhecimentos e assim reconhecer e conhecer os problemas do mundo é necessária a reforma do pensamento (Morin, 2011, p. 33).

Cabe, assim, ao professor focalizar as aprendizagens fundamentais, conforme assinala Oliva (2011, p. 29, grifos do autor): "Os objetos do conhecimento precisam ser os reais e não os aparentes ou ilusórios (...)", para que os estudantes sejam capazes de promover leituras mais acertadas do mundo e da sua realidade, para nela intervir, resolvendo assim a questão destacada por Morin (2011, p. 38), de que "os problemas fundamentais e os problemas globais estão ausentes das ciências disciplinares".

O ensino de mudanças climáticas e temas associados a ela, segundo Orion (2019), deve fomentar uma postura crítica, para que assim seu entendimento e compreensão sejam engajados por meio de um processo de aprendizagem significativa, haja vista seu potencial de desenvolvimento associado à resolução de problemas reais, já que tais temas costumam apresentar grande relevância e interesse para os estudantes. Isso quer dizer que uma educação em mudanças climáticas deve ser capaz de fornecer explicações confiáveis aos estudantes, apresentando formas plausíveis de compreensão e interpretação sobre o tema: "(...) mudanças climáticas deveriam ser entendidas como uma complexidade social assim como uma temática científica caracterizada por contextos específicos e incertos (Stevenson et al., 2017, p. 67).

Segundo Monroe et al. (2019), o ensino de mudanças climáticas tem enfrentado algumas dificuldades por parte dos professores, sendo que a principal delas é encontrar estratégias para a escolha e/ou definição de uma abordagem metodológica a serem adotadas em sala de aula. Outro ponto relatado pelos docentes é o excesso de (des) informação, o que compromete o desenvolvimento da interdisciplinaridade, inerente ao estudo das mudanças climáticas.

\begin{tabular}{c|c|c|c|c|c}
\hline (C) Terrae Didat. & Campinas, SP & v.17 & $1-12$ & $\mathrm{e} 021052$ & 2021 \\
\hline
\end{tabular}


Os professores enfrentam, pois, o desafio de promover uma educação integral, capaz de formar alunos aptos a viver em um mundo plural, fluido e complexo, do qual a incerteza faz parte. As transformações trazem a necessidade de novos processos de ensino e de aprendizagem, orientadas por caminhos e práticas pedagógicas que estejam fundamentadas no protagonismo discente. Segundo Fortner (2001, p.19),

(...) a preparação para as responsabilidades cidadãs em uma sociedade global, assim como desenvolver estilos de vida individuais sustentáveis deve ditar como a mudança climática global deve aparecer na educação formal (Fortner, 2001, p.19).

O ensino de mudanças climáticas precisa se assentar em iniciativas pedagógicas ativas, processos de ensino e de aprendizagem, recursos e métodos que ensejem a interdisciplinaridade, já que, somente assim, será possível “(...) evitar a visão unidimensional abstrata” (Morin, 2015, p. 11).

Assim, a Aprendizagem Baseada em Projetos (ABP), ao explorar temas do contexto dos estudantes, propõe experiências significativas de aprendizagem, evidenciando-se como uma poderosa estratégia de exploração conceitual reflexiva, fundamentada em um problema real, do cotidiano dos estudantes. A ABP “(...) pode ser definida pela utilização de projetos autênticos e realistas, baseados em uma questão, tarefa ou problema altamente motivador e envolvente, para ensinar conteúdos acadêmicos aos alunos no contexto do trabalho cooperativo para a resolução de problemas" (Bender, 2014, p. 15).

Siegner \& Stapert (2020) alertam para a relevância do ensino de mudanças climáticas: não é possível uma abordagem a partir de uma única perspectiva (de uma única componente curricular). Sendo inerentemente interdisciplinar, seus processos e abordagens pedagógicas devem se pautar pelo entendimento dos conceitos que estruturam sua compreensão sem excesso de abstrações e modelos. Ao contrário, de forma muito mais ampla, trata-se de fomentar “(...) estratégias de raciocínio da habilidade de buscar, selecionar e tratar informações; de trabalhar em equipe; de solucionar problemas complexos, entre outros" (Faria \& Vaz, 2017, p. 163). Sendo assim, "O ensino na ABP é mais apropriado para preparar os alunos com habilidades de resolução de problemas e tecnologias do século XXI" (Bender, 2014, p. 25 , grifo das autoras).
Monroe et al. (2019) chamam a atenção para que o ensino de mudanças climáticas seja proposto por meio de abordagens ativas, relacionadas às estratégias de ensino e de aprendizagem que coloquem o estudante no centro desse processo, para que ele assuma o protagonismo da aula, rompendo reducionismos e fragmentações. Para tanto, acreditam que pesquisar e investigar, por exemplo, efeitos das mudanças climáticas na realidade circundante seja um excelente ponto de partida, já que:

Aqueles que ensinam mudanças climáticas têm o desafio de criar uma atmosfera acolhedora para uma diversidade de perspectivas sobre as mudanças climáticas, ao mesmo tempo que dissipam as concepções erradas dos estudantes sobre as ciências climáticas, que são muitas vezes fortemente apoiadas por fatores sócio-culturais.O desafio da educação sobre as alterações climáticas sugere que o tipo de educação que sempre fizemos pode não ser suficiente para envolver os alunos na tarefa metacognitiva de compreender como pensar e questionar a justificativa das suas ideias (Monroe et al., 2019, p. 16).

\section{Procedimentos metodológicos: elaboração da sequência didática}

Para a abordagem pedagógica das questões relacionadas à habitação, clima e direitos básicos do cidadão, parte-se do princípio que o dever de proteção do Estado vai além da criação de leis que regulamentem o espaço urbano, devendo, com seu arcabouço normativo, elaborar normas que efetivem a responsabilidade socioambiental para proteger as gerações contra os riscos advindos das alterações climáticas, tais como as supracitadas Plano Nacional de Educação em Direitos Humanos (Brasil, PNEDH, 2007) e Diretrizes Nacionais para Educação em Direitos Humanos, DNEDH (Brasil, 2012).

A partir desse ponto, verifica-se que a Base Nacional Comum Curricular (BNCC) estabelece que a etapa do Ensino Médio seja dividida em áreas do conhecimento. Para este trabalho elegeu-se a área de Ciências Sociais Humanas e Aplicadas, que, por sua vez, é composta de seis competências gerais, a serem trabalhadas e desenvolvidas ao longo de toda a etapa pelas componentes curriculares que dela fazem parte - como a Geografia - e suas respectivas habilidades. No estudo que embasa este artigo, trabalhar-se-á com a competência 3: 
Analisar e avaliar criticamente as relações de diferentes grupos, povos e sociedades com a natureza (produção, distribuição e consumo) e seus impactos econômicos e socioambientais, com vistas à proposição de alternativas que respeitem e promovam a consciência, a ética socioambiental e o consumo responsável em âmbito local, regional, nacional e global (Brasil, 2017, p. 574).

A temática da habitação e moradia nas cidades foi selecionada por ser um problema comum às grandes cidades brasileiras, independentemente de sua região/Estado e do porte da cidade e pode ser relacionada aos assuntos dos direitos fundamentais dos cidadãos. Adicionalmente, a temática é interessante porque tal situação atinge aqueles que são os mais vulneráveis e, portanto, mais suscetíveis aos efeitos negativos da mudança climática. Para assegurar a aprendizagem relacionada à construção da competência 3 (três), elege-se a habilidade identificada como EM13CHS304:

Analisar os impactos socioambientais decorrentes de práticas de instituições governamentais, de empresas e de indivíduos, discutindo as origens dessas práticas, selecionando, incorporando e promovendo aquelas que favoreçam a consciência e a ética socioambiental e o consumo responsável (Brasil, 2017, p. 575).

A fim de construir e desenvolver a competência específica e a habilidade, trazendo à tona o problema da moradia e habitação frente às mudanças climáticas que, por sua vez, alude às questões acerca dos direitos fundamentais dos cidadãos e da justiça climática, foi utilizada a Sequência Didática (SD), dentro da abordagem da ABP proposta por Bender (2014). A SD é dividida em 6 etapas, sendo elas:

- Brainstorming

- Âncora e Questão Motriz

- Processo de Investigação

- Confecção do Artefato Final - Objeto Didático-Digital de Aprendizagem (ODDA)

- Discussão e Conclusão-Apresentação pública dos resultados

\section{- Auto-Avaliação}

A SD foi elaborada com base nos termos da metodologia ABP, elucidados por Bender (2014, p. 16-17 e 32), utilizando-se como recurso didático de investigação na internet a WebQuest, cujos fundamentos encontram-se em Bacich (2020), assim como ferramentas tecnológicas web 2 , compostas por softwares gratuitos como Mentimeter, Padlet, Google Sites e Canva. A WebQuest é um conjunto de atividades e procedimentos associados à metodologia de ensino baseada em projetos que os estudantes precisam resolver como parte do desafio e para construir o "Artefato final", aqui denominado Objeto Didático-Digital de Aprendizagem (ODDA). O processo da SD e as ferramentas tecnológicas utilizadas em cada etapa estão descritos no esquema da Figura 1.

A primeira etapa da SD, que consiste no levantamento de conhecimentos prévios dos estudantes, busca utilizar o brainstorming ou "chuva de ideias" como estratégia, conforme proposto por Bender (2014). O material fornece subsídios para que o professor, mais adiante, realize a mediação acerca do tema escolhido (no caso aqui, mudanças climáticas, habitação e direitos básicos do cidadão).

A etapa foi realizada por meio da ferramenta Mentimeter (mentimeter.com). É necessário que, antes da aula, o professor prepare o Mentimeter para que os estudantes, via "link" ou "QR code", possam acessar e preencher. Essa atividade pode ser feita por meio de dispositivos como smartphones, por exemplo. O professor é quem determina quantas palavras ficam liberadas para o preenchimento de seus estudantes, para compor a nuvem de palavras.

$\mathrm{Na}$ segunda etapa da SD, após o brainstorming, os alunos tomarão contato, pela primeira vez, com o objetivo de pesquisa e, segundo a ABP, acessarão a âncora, conforme proposto na metodologia de Ben$\operatorname{der}(2014$, p. 32). Como âncora e questão motriz, neste trabalho utilizou-se o texto produzido pelo Instituto Nacional de Pesquisas Espaciais (INPE) denominado Sumário das mudanças no clima projetadas pelo INPE CCST para o Brasil atéfinal do século XXI, para um cenário de altas emissões, de José Marengo

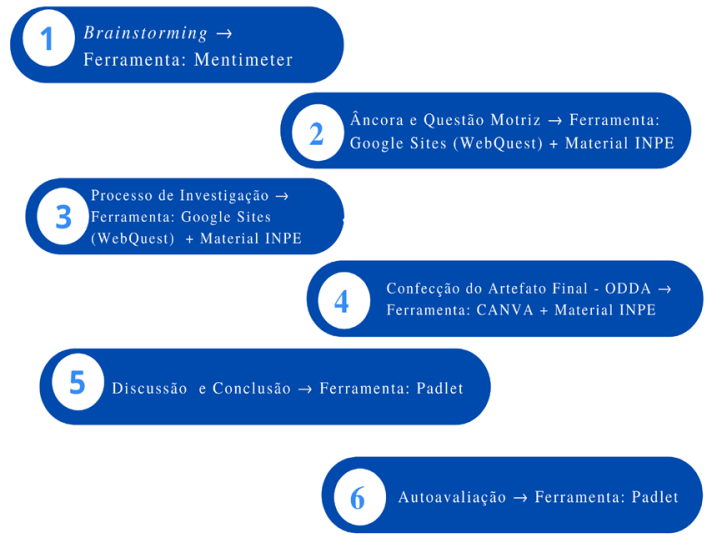

Figura 1. Esquema da montagem da Sequência Didática (SD), elaborado em Canva

\begin{tabular}{c|c|c|c|c|c|c}
\hline (C) Terrae Didat. & Campinas, SP & v.17 & $1-12$ & $\mathrm{e} 021052$ & 2021 \\
\hline
\end{tabular}


(http://mudancasclimaticas.cptec.inpe.br/). O texto deverá ficar disponível no menu < Introdução >, previamente preparado pelo professor na ferramenta Google Sites. O SITE DO PROJETO está disponível em https://sites.google.com/view/webquest-mudancas-climaticas/introdu $\% \mathrm{C} 3 \% \mathrm{~A} 7 \% \mathrm{C} 3 \% \mathrm{~A} 3 \mathrm{o}$. Ressalta-se que, a depender da temática escolhida pelo docente, novos textos podem ser incluídos e trabalhados em substituição a esse.

Para as etapas três e quatro da SD proposta, os estudantes devem acessar o SITE DO PROJETO; no menu $<$ Tarefa $>$ estão propostas as atividades. No caso da SD deste trabalho, foi sugerida uma primeira leitura de um material do INPE, disponível em http://mudancasclimaticas.cptec.inpe.br/, disponível no item <Produtos $>$ e em uma apresentação powerpoint que foi anexada ao site; na sequência, sugere-se uma atividade de destacar os principais problemas socioambientais da região do qual o grupo faz parte. O próximo passo, dentro do item $<$ Processo $>$, também do SITE DO PROJETO, contém as orientações para os alunos realizarem, conforme a metodologia ABP proposta por Bender (2014, p. 32), as conexões, propostas e projetos entre o problema elencado e os direitos básicos do cidadão. Em seguida, é solicitado que o aluno prepare uma apresentação por meio do Canva (https://www. canva.com/, software também online e gratuito).

$\mathrm{Na}$ quarta etapa da SD é proposto que os estudantes pesquisem sobre os problemas socioambientais relacionados às mudanças climáticas, criando oportunidade para reflexão (Bender, 2014, p. 16, Bacich, 2020). Com base nas pesquisas e no que foi discutido anteriormente, é solicitado que o aluno construa o seu "artefato final" conforme proposto por Bender (2014), aqui denominado de ODDA. Os estudantes devem seguir para a quinta etapa, que consiste na apresentação pública dos resultados, por meio das conclusões e discussões. Por fim, como prevê a ABP, na sexta etapa, os alunos deverão realizar a avaliação do processo que, nesse caso, se sugere a auto-avaliação.

\section{Resultados e Discussão}

Todos os sites e processos realizados nesse trabalho estão disponíveis online para consulta de interessados no site do CEPAGRI da Unicamp. A ideia é que os pro- fessores utilizem essa metodologia proposta de SD para os problemas reais ou temas de interesse de suas regiões/cidades, afinal, como coloca Freire (1996, p. 07) “(...) por que não discutir com os alunos a realidade concreta a que se deva associar a disciplina cujo conteúdo se ensina?"

Seguindo, então, os princípios da ABP de Bender (2014), nesta sugestão de SD, a primeira etapa levanta os conhecimentos prévios dos estudantes acerca do tema mudanças climáticas e gera resultados conforme apresentados na Figura 2. O professor então, terá acesso ao que os estudantes previamente entendem no tema selecionado. As palavras geradas pelo Mentimeter apresentam tamanhos e, quanto maior for o tamanho da palavra, significa que mais alunos escolheram essa palavra. No exemplo da Figura 2, uma maior quantidade de pessoas escolheu "aquecimento global" como sendo representativo para o tema "Mudanças Climáticas". Vale ressaltar que o levantamento dos conhecimentos prévios dos alunos é fundamental para o professor guiar o processo de ensino e aprendizagem, já “(...) a meta é produzir o máximo possível de ideias para a resolução de tarefas (...)" (Bender, 2014, p. 17).

A introdução, disponível na abertura do SITE DO PROJETO, é importante para iniciar a discussão do assunto selecionado pelo professor, segundo Bender (2014, p. 32) “(...) introdução e informações básicas para preparar o terreno e gerar o interesse dos alunos (...)".Ressalta-se aqui que, nesse momento, é importante que o professor conduza a mediação do processo para que os alunos sejam capazes de verificar em quais temas sua pesquisa precisa concentrar mais esforços, bem como a forma como ela deverá ser direcionada.

\section{O que você entende por mudança climática?}

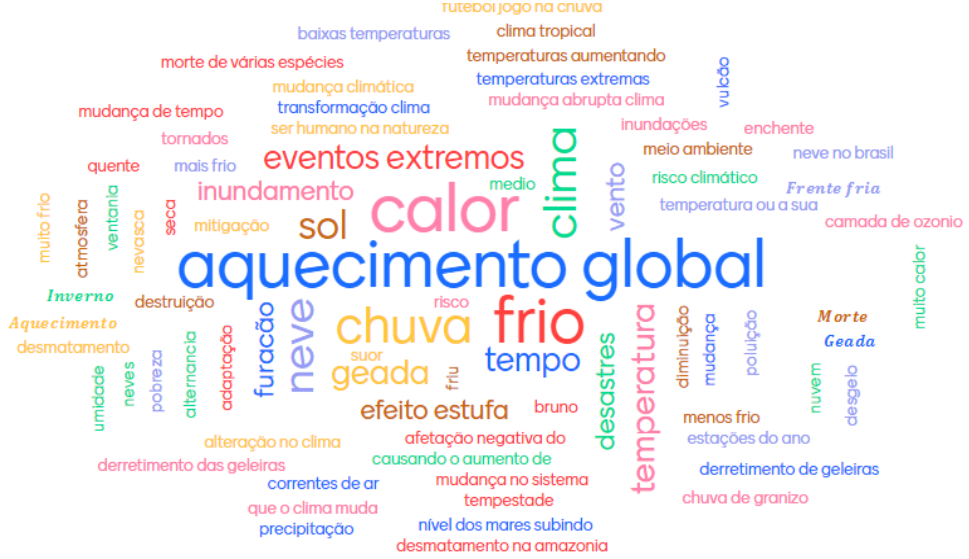

Figura 2. Resultados do Mentimeter-Brainstorming em formato de nuvem de palavras

\begin{tabular}{c|c|c|c|c|c|}
\hline (C) Terrae Didat. & Campinas, SP & v.17 & $1-12$ & $\mathrm{e} 021052$ & 2021 \\
\hline
\end{tabular}




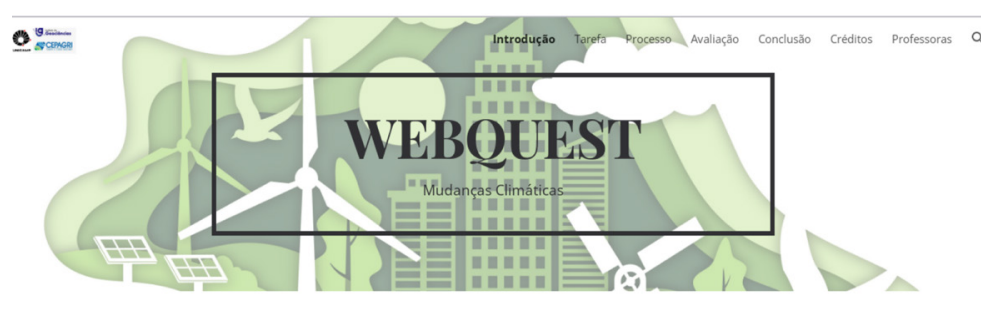

Introduçăo - 0 que são mudanças climáticas?

Segundo o INPE,

As mudanç̧as climáticas antropogênicas, ou seja, aquelas causadas pelo homem, estão associadas ao aumento da emissão de gases de efeito estufa por queima de combustiveis fósseis (dos automóveis, das indústrias, usinas termoelétiticas), queimadas, desmatamento, decomposig̨ăo de lixo etc. A partir do fina do sêculo 18 (Revoluçāo Industrial) e na segunda metade do século 20, houve uma expansăo da produçăa industrial, o que gerou um grande aumento de emissöes de gases de efeito estufa ne atmosfera. Existem fortes indicios de que o clima está de fato mudando. As décadas de 1990 e 2000 foram as mais quentes dos üttimos 1.000 anos. As projeçōes do Painel Intergovernamental de Mudanças Climáticas (IPCC) indicam que nos próximos 100 anos poderá haver um aumento da temperatura méclia global entre $18^{\circ} \mathrm{C}$ e $40^{\circ} \mathrm{C}$ e um aumento do nivel médio do mar entre $0.18 \mathrm{~m}$ e $0.59 \mathrm{~m}$ o que pode afot significativamente as atividades humanas e os ecossistemas terrestres

(Disponivel em http//wwwinpe.brffaglindex.php?pai=9 - Acesso: 22/ju/2021)

Figura 3. Site gerado pelo Google Sites com a proposta de WebQuest para realização da SD sobre o tema escolhido pelo professor

Dividido em $<$ Tarefa $>,<$ Processo $>,<$ Avaliação $>$ e $<$ Conclusão $>$, as abas vão propondo as atividades a serem realizadas. $\mathrm{Na}$ etapa $<$ Tarefa $>$ (https://sites.google.com/view/webquest-mudancas-climaticas/tarefa), os estudantes são convidados pelo professor a realizarem um processo de investigação, no qual “(...) pode-se usar diretrizes para a conclusão do projeto e geração de artefatos para estruturar o projeto" (Bender, 2014, p. 32). Nesse momento, o professor deve mediar as discussões dentro da realidade vivida pelos estudantes, abordando os impactos relacionados a mudanças climáticas para que os estudantes sejam capazes de inferir e avaliar em que medida eles afetam mais intensamente as populações mais vulneráveis. A mediação realizada pelo professor deverá estar embasada no levantamento dos conhecimentos prévios:

(...) a incorporação do pensamento crítico no contexto da alfabetização científica ocorre em função da compreensão da ciência como um conhecimento aplicado ao cotidiano e presente nas tomadas de decisão de forma crítica no sentido de sua validade (Façanha et al., 2019, p. 46).

$\mathrm{Na}$ aba seguinte, do $<$ Processo $>$ (Fig. 5), o aluno é convidado a construir o artefato denominado ODDA sobre o tema discutido (https:// sites.google.com/view/webquest- -mudancas-climaticas/processo). Nesse momento, segundo Bender (2014, p. 32), é preciso “(...) criar oportunidades para a reflexão dos alunos (...)" para que os estudantes sejam capazes de criar os artefatos. Em ABP,

(...) O termo artefato é usado para enfatizar que nem todos os projetos resultam em um relato escrito ou em uma apresentação. Os artefatos podem incluí-los, mas também podem abranger vídeos digitais, portifólios, podcasts, websites, poemas... (Bender, 2014, p. 16, grifos do autor). Um exemplo de ODDA sobre Mudanças Climáticas criado pelas autoras para a aula está apresentado na Figura 6.

Por fim, para concluir o trabalho, os estudantes, na etapa cinco da SD, devem acessar o menu $<$ Conclusão $>$, disponível no SITE (https://sites. google.com/view/webquest-mudancas-climaticas/ conclus $\% \mathrm{C} 3 \% \mathrm{~A} 3 \mathrm{o}$ ) e preencher os dados no Padlet, que é um mural colaborativo-interativo (https://padlet.com/deba_rgt/mgvkbkppzuou58xa). A etapa é necessária para que o profes-

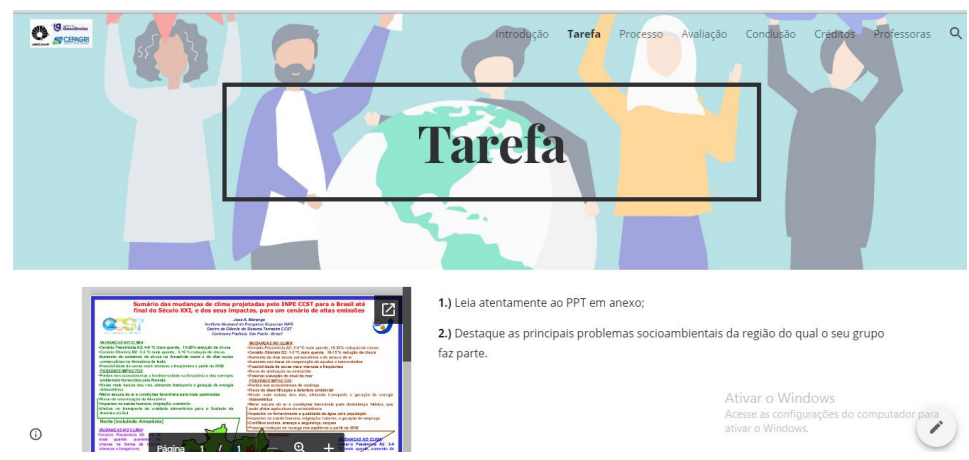

Figura 4. Aba <Tarefa $>$, que leva os alunos ao processo de Investigação Científica. URL: https://sites.google.com/view/webquest-mudancas-climaticas/tarefa)

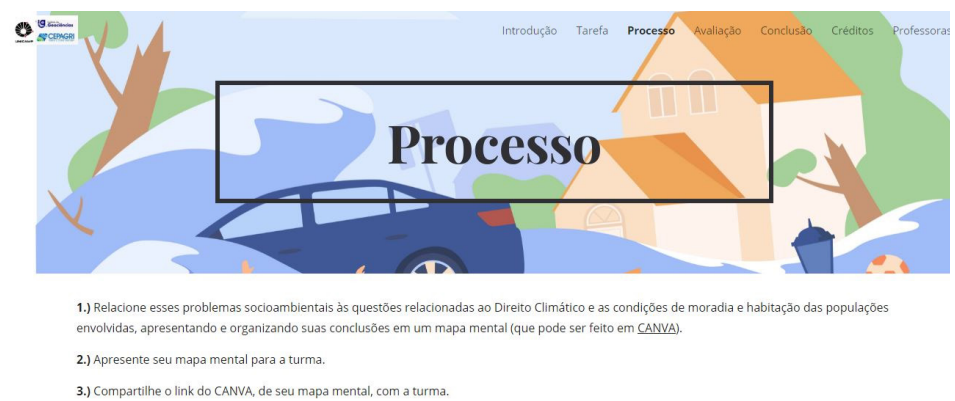

Figura 5. Aba < Processo > com indicações de como construir o ODDA

\begin{tabular}{c|c|c|c|c|c|}
\hline C Terrae Didat. & Campinas, SP & v.17 & $1-12$ & e021052 & 2021 \\
\hline \multicolumn{2}{|c|}{9}
\end{tabular}




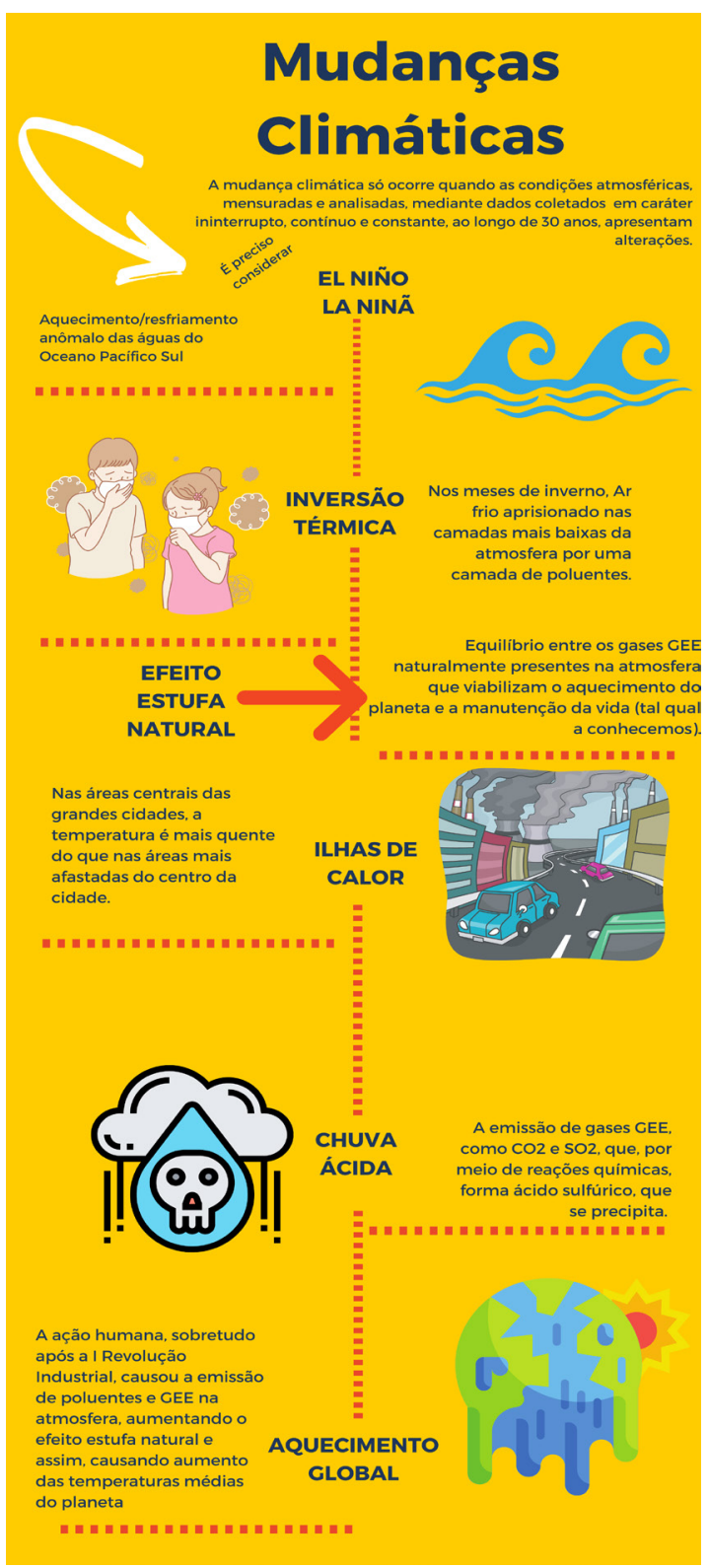

Figura 6. ODDA confeccionado em CANVA (https://bit. ly/3rpiYV4) e fundamentado em http://mudancasclimaticas.cptec.inpe.br/ sor organize a apresentação e as discussões, que serão finalizadas pelo preenchimento da Auto-avaliação no menu <Avaliação> (https://sites. google.com/view/webquest-mudancas-climaticas/ introdu $\% \mathrm{C} 3 \% \mathrm{~A} 7 \% \mathrm{C} 3 \% \mathrm{~A} 30)$. A Figura 7 apresenta um exemplo de discussão e apresentação dos resultados. É importante que os alunos sejam capazes de realizar a apresentação pública dos resultados, já que:

(...) os projetos de $\mathrm{ABP}$ pretendem ser exemplos autênticos dos tipos de problemas que os alunos enfrentam no mundo real, de modo que algum tipo de apresentação pública dos resultados do projeto é fundamental dentro da ABP (Bender, 2014, p. 32)

Nesse momento, é preciso que o professor tenha em mente que, na ABP, “(...) o estudante é agente ativo em sua aprendizagem” (Jacaúna \& Greco, 2019, p. 05). A Tabela 1 sintetiza os principais passos, atividades e as ferramentas/produtos elaborados na pesquisa.

\section{Considerações Finais}

A presente pesquisa descreve etapas de elaboração de uma proposta para o ensino e aprendizagem de tópicos em mudanças climáticas segundo as prerrogativas da BNCC, apresentada em uma sequência didática apoiada nos princípios da Aprendizagem Baseada em Projetos (ABP). Colocando o estudante como protagonista do processo, é possível ensinar mudanças climáticas e assuntos relacionados ao tema, por meio de sequências didáticas capazes de promover aprendizagem significativa. Estabelece-se um debate em sala de aula acerca dos direitos fundamentais dos cidadãos, incluindo noções sobre justiça climática e vulnerabilidade ante a problemática da moradia e da habitação nas

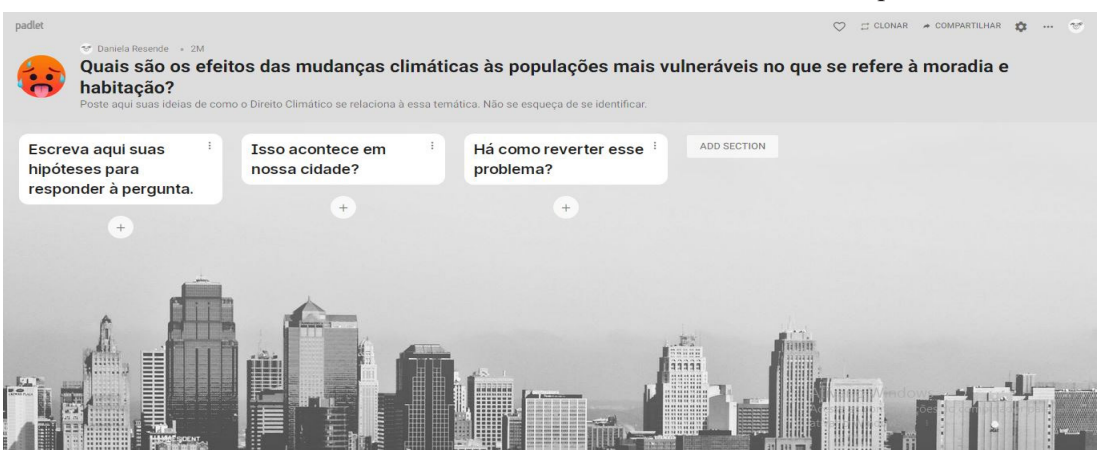
ocupações irregulares do solo urbano envolvendo problemas socioambientais. A metodologia aberta, os sites e os resultados estão disponíveis ao público para serem utilizados, quer da maneira como estão, quer para auxiliar o professor a desenvolver o seu próprio Figura 7. Apresentação e discussão pública dos resultados em Padlet, que deverá projeto dentro da temática ser preenchida colaborativamente pelos alunos (https://padlet.com/deba_rgt/ escolhida. mgvkbkppzuou58xa) 
Tabela 1. Passo a passo da SD. Elaborada pelas autoras

\begin{tabular}{l|l}
\hline Atividade & Ferramentas e/ou produtos \\
\hline Brainstorming & https://www.mentimeter.com/s/f4f864dba8cd398f06600cc1b6b49f7f/a3394beb1341 \\
\hline Âncora e Questão Motriz & http://mudancasclimaticas.cptec.inpe.br/ \\
\hline Processo de Investigação & https://sites.google.com/view/webquest-mudancas-climaticas/tarefa \\
\hline $\begin{array}{l}\text { Confecção do Artefato Final Objeto } \\
\text { Didático-Digital de Aprendizagem } \\
\text { (ODDA) }\end{array}$ & https://bit.ly/3rpiYV4 \\
\hline $\begin{array}{l}\text { Discussão e Conclusão } \\
\text { Apresentação pública dos resultados }\end{array}$ & https://sites.google.com/view/webquest-mudancas-climaticas/conclus\%C3\%A3o \\
\hline $\begin{array}{l}\text { Auto-avaliação } \\
\text { https://sites.google.com/view/webquest-mudancas-climaticas/avalia\%C3\%A7\%C3\%A3o }\end{array}$
\end{tabular}

Com a BNCC e as novas orientações para a Educação Básica brasileira, faz-se necessário buscar abordagens metodológicas que fomentem uma aprendizagem ativa e significativa, capaz de promover conexões que mobilizem conhecimentos para a resolução de problemas da vida real, já que a contextualização é fundamental na articulação teórico-prática.

O estudo permite concluir que a sequência didática pode ser replicada por docentes em diversos contextos de ensino e aprendizagem. A metodologia empregada é de fácil acesso e utilização. Utilizou-se a metodologia ABP com seus princípios e prerrogativas, associadas a um recurso de pesquisa muito simples - a WebQuest - que pode ser desenvolvido por meio de ferramentas colaborativas e de acesso gratuito.

\section{Referências}

Artaxo, P. (2020). As três emergências que nossa sociedade enfrenta: saúde, biodiversidade e mudanças climáticas. Estudos Avançados, 34, 53-66. doi: 10.1590/ s0103-4014.2020.34100.005

Bacich, L. (2020). WebQuest: como organizar uma atividade significativa de pesquisa. São Paulo, Inovação na educação. 22 de março de 2020. URL: https://lilianbacich.com/2020/03/22/webquest-como-organizar-uma-atividade-significativa-de-pesquisa/Acesso 23.07.2021.

Barcellos, C., Monteiro, A. M. V., Corvalán, C. Gurgel, H. C., Carvalho, M. S., Artaxo, P., Hacon, S., \& Ragoni, V. (2009). Mudanças climáticas e ambientais e as doenças infecciosas: cenários e incertezas para o Brasil. Epidemiol. Serv. Saúde, 18(3), 285-304. doi: 10.5123/S1679-49742009000300011

Bender, W.N. (2014). Aprendizagem baseada em projetos. Educação diferenciada para o século XXI. Porto Alegre: Penso.

Blank, D. M. P. (2015). O contexto das mudanças climáticas e as suas vítimas. Fortaleza: Mercator,14, 157172. doi: 10.4215/RM2015.1402.0010

Brasil, Comitê Nacional de Educação em Direitos Humanos (2007). Plano Nacional de Educação em Direitos Humanos. Brasília: Secretaria Especial dos Direitos
Humanos, Ministério da Educação, Ministério da Justiça, UNESCO. URL: http://portal.mec.gov. br/docman/2191-plano-nacional-pdf/file. Acesso 16.11.2021.

Brasil. Ministério da Educação. (2018). Base Nacional Comum Curricular: versão final. Brasília, MEC. URL: http://basenacionalcomum.mec.gov.br/images/ BNCC_EI_EF_110518_versaofinal_site.pdf. Acesso $15.0 \overline{4} .20 \overline{2} 1$.

Brasil. Constituição (1988). Constituição da República Federativa do Brasil [online]. Brasília, DF: Senado Federal: Centro Gráfico. URL: http://www.planalto.gov. br/ccivil_03/constituicao/constituicao.htm. Acesso 12.07.2021.

Brasil. (2012). Lei 4771/1965. Código Florestal Brasileiro [online]. Brasília, DF. URL: http://www.planalto. gov.br/ccivil03/leis/L4771.htm. Acesso 12.07.2021.

Brasil. Ministério da Educação (2012). Diretrizes Nacionais para a Educação em Direitos Humanos. Resolução $n^{\circ} 1$, de 30.05.2012. Brasília, DF: Diário Oficial da União, 21.maio.2012, Seção 1, p. 48. URL: http://www. planalto.gov.br/ccivil_03/_Ato2007-2010/2009/Decreto/D7037.htm. Acesso 09.09.2021.

Brasil. Superior Tribunal de Justiça (STJ) (2009). Recurso Especial: REsp 1000731 RO 2007/0254811-8. Relator: Ministro Herman Benjamin. Data de Julgamento: 25/08/2009, T2 Segunda Turma, Data de Publicação: DJe 08/09/2009. Brasília, DF: STJ. URL: https://processo.stj.jus.br/processo/revista/ inteiroteor/?num registro $=200702548118 \& \mathrm{dt}$ publicacao $=08 / 09 / 2009$. Acesso 28.11.2021

Façanha, A. A. B., Chianca, R. C., \& Félix, C. P. (2019). O pensamento crítico no contexto da alfabetização científica: um estudo com futuros professores de ciências. Revista Ciências \& Ideias, 10(2), 42-55. URL: https://revistascientificas.ifrj.edu.br/ revista/index.php/reci/article/view/946/677. Acesso 12.03.2020.

Faria, A. F., \& Vaz, A. M. (2018). Experiências de Pensamento Científico em aulas de Física. Investigações em Ensino de Ciências, 23(1), 266-294. 10.22600/15188795.ienci2018v23n1p266.

Fernandes, L. C. S. (2020). Unicidade do Direito para a proteção ambiental. Revista Internacional da Academia Paulista de Direito, (6), 21.

Fortner, R. W. (2001). Climate change in school: where does it fit and how ready are we? Canadian Journal of Environmental Education (CJEE), 6(1), 18-31. URL: https://cjee.lakeheadu.ca/article/view/285. Acesso 28.12.2020. 
Freire, P. (1996). Pedagogia da autonomia: saberes necessários à prática. São Paulo: Paz e Terra.

Grostein, M. D. (2001). Metrópole e expansão urbana: a persistência de processos "insustentáveis". São Paulo em perspectiva, 15, 13-19. doi: 10.1590/S010288392001000100003.

Jacaúna, C. L. F. S., \& Greco, R. (2019). Ensino por projeto: uma experiência com estudantes de escolas de várzea no amazonas. Geografia ensino \& pesquisa, 23, 1-17. URL: https://periodicos.ufsm.br/geografia/article/view/39980. Acesso 31.08.2021.

Levy, B. S., \& Patz, J. (2015). Climate change, human rights, and social justice. Annals of Global Health, 81(3), 310-322. doi: 10.1016/j.aogh.2015.08.008.

Morin, E. (2011). Os sete saberes necessários à educação do futuro. São Paulo: Cortez; Brasília, DF: UNESCO.

Morin, E. (2015). Introdução ao pensamento complexo. Porto Alegre: Sulina.

Monroe, M. C., Plate, R. R., Oxarart, A, Bowers, A., \& Chaves, W. A. (2017). Identifying effective climate change education strategies: a systematic review ofthe research, Environmental Education Research, 25(6), 791-812. doi: 10.1080/13504622.2017.1360842.

Oliva, A. (2011). Teoria do Conhecimento. Rio de Janeiro: Zahar.

Organização das Nações Unidas (ONU). (2019). Informe sobre a Questão das Obrigações de Direitos Humanos Relacionadas com o Gozo de um Meio Ambiente Seguro, Limpo, Saudável e Sustentável (A/74/161). ONU, Relator especial sobre Direitos Humanos e Meio Ambiente do Alto Comissariado de Direitos Humanos., par. 65, 22p. URL: https://documents-dds-ny.un.org/ doc/UNDOC/GEN/N19/216/45/PDF/N1921645. pdf?OpenElement. Acesso 27.11.2021.

Orion, N. (2019). The future challenge of Earth science education research. Disciplinary and Interdisciplinary Science Education Research, 1(1), 3-8. URL: https:// link.springer.com/article/10.1186/s43031-0190003-z. Acesso 12.12.2020.

Palma, C. M. (2018). Do Direito Ambiental à Educação Ambiental. Contribuições do pensamento vida e obra de Paulo Afonso Leme Machado. São Paulo: Letras Jurídicas.

Piovesan, F. C. (2009). Direitos humanos: desafios e perspectivas contemporâneas. Brasília, Revista TST, $75(1)$.

Ramacciotti, B. L., Souza, C. Q. da, \& Dantas, L. R. A. S.
(2020). O princício da proibição do retrocesso ambiental aplicado às políticas públicas ambientais. [S.l.], REI, Revista de Estudos Institucionais, 6(2), 685-706. ISSN 2447-5467. doi: 10.21783/rei.v6i2.481.

Santos, V. M. N. dos \& Bacci, D. L. C. (2017). Proposta para governança ambiental ante os dilemas socioambientais urbanos. Estudos Avançados, 31, 199-212. doi: 10.1590/s0103-40142017.31890017.

Sachs, W. (2008). Climate change and human rights. Development, 51(3), 332-337. doi: 10.1057/dev.2008.35.

Sagala, R., Nuangchalerm, P., Saregar, A., El Islami, R. A. Z. (2019). Environment-friendly education as a solution to against global warming: a case study at Sekolah Alam Lampung, Indonesia. Journal for the Education of Gifted Young Scientists, 7(2), 85-97. URL https://dergipark.org.tr/en/pub/jegys/article/565454. Acesso 12.12.2020.

Sarlet, I. W., \& Fensterseifer, T. (2021). Curso de Direito Ambiental. 2ed. Rio de Janeiro: Forense. p. 390-399.

Siegner, A. \& Stapert, N. (2020). Climate chance education in the humanities classroom: a case study of Lowell School curriculum pilot. Environmental Education Research, 26, 511-531. doi: 10.1080/13504622.2019.1607258.

Silva, C. P. da, Figuerôa, S. F. M., \& Newerla, V. B. (2008). Subsídios para o uso da história das ciências no ensino: exemplos extraídos das Geociências. Ciência E Educação (Bauru), 14, 497-517. URL: https://www. scielo.br/j/ciedu/a/h8SpWTgmpxZDQrgCCPjn $5 \mathrm{NF} / \mathrm{abstract} /$ ?format $=$ html\&lang $=$ pt. Acesso 22.08.2021.

Sinden, A. (2007). Climate change and human rights. J. Land Resources \& Envtl. L., 27, 255-271.

Souza, J. A. G. de (coord.) (2008). A Defensoria Pública e os processos coletivos: comemorando a Lei Federal 11.448, de 15 de janeiro de 2007. Rio de Janeiro: Lúmen Juris.

Stevenson, R. B., Nicholls, J., Whitehouse, H.(2017). What is climate change education? Curriculum Perspectives, 37(1), 67-71. URL: https://link.springer. com/article/10.1007/s41297-017-0015-9. Acesso 15.12.2020.

Zezzo, L. V., Oliveira, J. P. de, \& Coltri, P. P. (2020). Clima em jogo: uma ferramenta pedagógica para aprendizagem de conceitos em Geociências, com ênfase na Climatologia. Terre Didatica, 16(Publ. Contínua), 1-10, e020003. doi: 10.20396/td.v16i0.8656203. 